\title{
PROJECT EVALUATION USING COST-TIME INVESTMENT SIMULATION
}

\author{
Kremljak, Z. ; Palcic, I.* \& Kafol, C. \\ *Telekom Slovenia Group (ONE Skopje), Cigaletova 15, 1000 Ljubljana, Slovenia \\ ** University of Maribor, Faculty of Mechanical Engineering, Smetanova 17, 2000 Maribor, Slovenia \\ E-Mail: zvonko.kremljak@one.mk
}

\begin{abstract}
Project success includes time, budget, quality, customer satisfaction etc. We are always confronted with time and money in the first place. Activity schedules must consider the available resources to be completed in the right sequence and in time. Companies must maintain competitive cost-time profiles. Execution periods of non-critical project activities have a considerable influence to the amount of locked-up capital. In the paper we have simulated some cases with varied execution periods of noncritical project activities within the slack, and measured cost-time investment. For the visualisation of project cost accumulation we have applied cost-time profile; we have used Cost Time Profiler software. The results show that the differences are significant, bringing a potential for project optimization.

(Received in December 2013, accepted in May 2014. This paper was with the authors 3 months for 1 revision.)
\end{abstract}

Key Words: Project, Activity, Slack Time, Cost-Time Profile, Investment

\section{INTRODUCTION}

Projects are nowadays one of the principal means by which we change the globalised world and project management has become one of the most popular tools for organisations to improve internal operations, respond rapidly to external opportunities, achieve technological breakthroughs, streamline new product development, and more robustly manage the challenges arising from their business environment. We can easily argue that project management has become a critical component of successful business operations in worldwide organisations today [1].

Definitions of project success can be very elusive. Among all success criteria, factors and frameworks, costs and time remain the most important ones. They are also extremely interdependent, especially in the field of project scheduling. The project duration is set by the project critical path, where the focus is on critical activities. But non-critical activities also play a vital role in project success as their start and finish times directly influence the capital invested in the project. In order to simulate different scenarios of project schedules based on non-critical activities delay and cost-time trade-offs we have introduced the concept of CostTime Profile in project management, a simple, graphical tool that considers both dimensions of cost (money amount and timing), and the resulting Cost-Time Investment.

The paper is structured as follows. Section 2 briefly presents the importance of project management and projects with a special focus on project success in terms of costs and time trade-off. Section 3 introduces the Cost-Time Profile concept with its application in project management area. The fourth section presents a case study of selected project "New product introduction to market", including cost-time profile simulation of different activities schedules. Section 5 documents the empirical findings and provides an analysis and discussion of the results. Finally, we conclude the paper with a summary of the findings, and directions for future research. 


\section{PROJECT SUCCESS AND COST-TIME TRADE-OFF}

According to Bender [2] one of the most important reasons for organisations to engage in projects and project management is adding value to an organisation. Companies and other organisations race to increase their value in different meaning of this word: value of their assets, value of products and services, customer perceived value etc. Bender [2] therefore argues that adding value is the most important goal of projects and project management and defines projects as the actions organisation performs to increase its value.

There are many definitions of projects and based on several authors we can define it as a sequence of unique, complex and connected activities that have one goal or purpose and that must be completed by a specific time, within budget, and according to specification. [3, 4]. Projects are limited by budget, schedule and resources - project work requires that members work with limited financial and human resources for a specified time period. Until completion projects and their activities are constrained by limitations on budget and personnel availability $[5,6]$.

Cost, time and quality (scope / performance) have always been inextricably linked with measuring the success of project management. These three variables present "the iron triangle" or so-called "triple constraint" and they were once the standard by which project performance was measured [7].

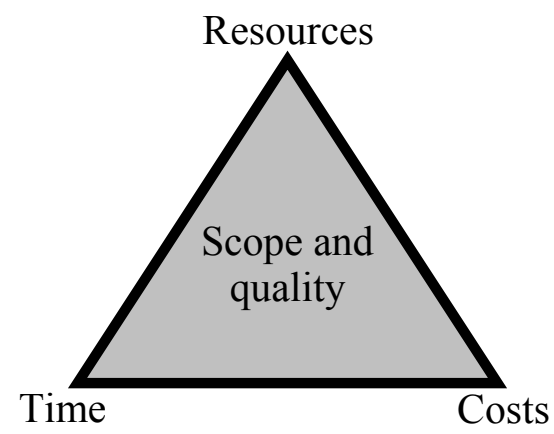

Figure 1: Iron triangle of project success.

Iron triangle criteria are still popular, particularly in the engineering, construction, and information technology fields because they can be made objective, tangible, and measurable $[8,9]$; they fall within the ambit of the project organisation [10]; they are short-term, ending upon project delivery [8-10]; and they can be used to evaluate a project manager's performance $[11,12]$.

If the project fulfils the performance, time and costs criteria, it is said to be efficient. The relationship between all three criteria emphasizes the fact that we have to find an appropriate balance between performance, time and costs [13]. It is practically impossible to improve one of these criteria without influencing the other two. Kerzner [3] also argues that very few projects are ever completed without trade-offs or scope changes on time, cost, and quality.

Nowadays, project success must be measured differently. It should be measured on more than the "triple constraint" criteria of schedule, budget, and specification. Being efficient is not enough. Therefore, later, a fourth criterion has been added: customer acceptance [3]. The definition of success can also vary according to who the stakeholder is. It is not possible to make all stakeholders happy, so it is important to prioritise them according to the power that they can wield and the impact that the project will have on them. Some stakeholders have the power to influence the project, while others will be able only to voice opinions [6]. Project success has also been extended to encompass the achievement of a broader set of organisational objectives, involving benefits to a wider range of stakeholders, including senior 
managers and project sponsors. In particular, attention has focused on the immediate and direct impact of the project on the organisation, including whether the business case and objectives for the project investment have been met and benefits to the business realized. Project success may even be extended further to include the accomplishment of more strategic objectives and benefits, including impacts on markets and competitors, business development or expansion, and ability to react to future opportunities or challenges [11, 14-16].

This papers focuses on two project success dimensions: time and costs. Projects cost time and money. The value of the projects must be greater than the expense incurred. Project management must also add value as with all activities organisation undertakes project management must reduce the cost and time for completing projects. It is also a fact that time and costs in projects are extremely interdependent. Project delays will always rise project costs. Attempt to shorten project duration will also increase project costs - so called project crashing. This paper introduces the concept of cost-time profile in the field of project management to analyse cost-time trade-off in a specific project scheduling area.

\section{COST-TIME PROFILE IN PROJECT MANAGEMENT}

A Cost-Time Profile (CTP) is a graph that depicts the accumulated costs that have been expended during the execution of a project at every time unit during the process. This way of presenting the information follows the use of resources through time, from the moment the execution begins until the company recovers those invested resources through the sale of the product. The area under the CTP is called the Cost-Time Investment $(C T I)$, because it presents how much money has been tied up in the manufacturing process and for how long before being recovered through sales [17]. Fig. 1 gives a simple illustration of a CTP.

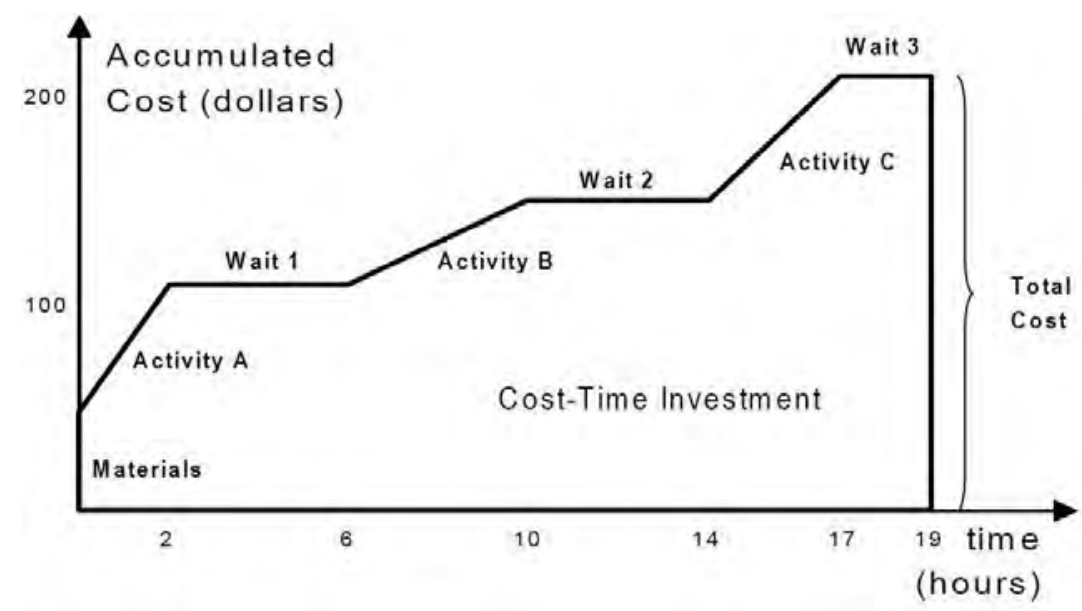

Figure 2: Example of a Cost-Time Profile [18].

There are several important parts on a CTP. Activities are the parts that actively add cost. They are represented by positive slope lines. Some activities require materials to be performed. The assumption is that the materials arrive right at the beginning of the activity and all at once, therefore they are represented by a vertical line (instantaneous accumulation of cost). Waits are moments when nothing that adds cost is actively happening. Waits are of interest, because in projects there is always some cost happening (overhead), even if you are not actively operating on the project. Since they do not add cost, they are represented by flat lines in the CTP curve (the accumulated cost remains constant during the wait). Total cost is the height of the curve at the end of the project. It represents the total accumulated cost of the project. However, this total cost does not reflect the effect of time on the investment. CTI is 
the area under the CTP curve, and it represents how much money and for how long has it been invested in the project (it consists of cost and time dimensions). This is a measure of the utilization of working capital, and since it is capital we are using, this capital will undoubtedly have a cost that will be whatever rate the company has to pay for its working capital. Its cost value can be obtained by multiplying it by the appropriate interest rate, for example, the Internal Rate of Return (IRR) [17-20].

Direct costs include labour, materials, and any other costs directly related to project activities. The Direct Cost is obtained as follows:

$$
\text { Direct Cost }=\text { Total Cost }+(\text { Cost-Time Investment } \times \text { Cost-of-Money-Rate })
$$

CTP does not consider indirect costs because it is truly hard to assign these costs directly to activities or individual units of a product. However, in project management it is reasonable to assume that all resources, people and equipment that take part in the project are directly and completely assignable to the project. Therefore, CTP is especially applicable to projects and the full spectrum of costs is included in them [17]. Of course, for scheduling optimization, CTP and CTI could be applied in other fields too [21, 22].

It is a well-known fact that project scheduling aims at precedence relationships between activities with the objective to minimize the total completion time of a project. This means that we rarely focus on total $C T I$. We will present how focus on $C T I$ could influence our decision on project scheduling process. In presented research we have focused on non-critical activities. These activities have a certain time buffer (slack) and can be delayed. We usually delay non-critical activities to manage human and other resources on the project. Although careful delay of non-critical activities does not impact the critical path of the project and hence its duration, it can have influence on project costs. Therefore, we will use CTP methodology and simulate non-critical activities delay on project costs.

\section{CASE STUDY}

The presented research focuses on investigation of the applicability of the $C T I$ criterion at project implementation phase. For that purpose we have used a case of a smaller project with 12 activities and tested different scenarios. With the CTI simulation the comparison and appropriate conclusions with some specific guidelines are enabled.

Basic information about the selected project "New product introduction to market" including a very simple product is presented in Table I.

Table I: Project information.

\begin{tabular}{|c|l|c|c|}
\hline Activity & \multicolumn{1}{|c|}{ Description } & $\begin{array}{c}\text { Estimated } \\
\text { duration (h) }\end{array}$ & Predecessors \\
\hline A & Purchase of the equipment for the new product's manufacturing & 160 & - \\
\hline B & Trial run for production (test batch) & 90 & A \\
\hline C & Ordering of raw materials / tools and suppliers' selection & 75 & - \\
\hline D & Delivery of raw materials / tools & 75 & C \\
\hline E & Selection of the sales manager for the new product & 25 & - \\
\hline F & Selection of the advertising agency & 25 & E \\
\hline G & Selection of the advertising media & 25 & F \\
\hline H & Co-operation at the creation of the advertising information & 60 & G \\
\hline I & Selection of the salesmen for the new product & 50 & E \\
\hline J & Starting advertising activities and promotions & 75 & H, I \\
\hline K & Regular production of the new product & 150 & B, D, E \\
\hline L & Product launch to market & 25 & K, J \\
\hline
\end{tabular}


Activities A, C and E can begin immediately. All other activities have one or more predecessors which must be completed to enable their start.

For constructing the activity network we have applied Activity-on-Arrow (AOA) logic, where the arrow represents the activity and the node signifies a link between events that suggests the completion of one activity and the potential to start the next. Network analysis has been done with the Critical Path Method (CPM). The results are given in Fig. 3.

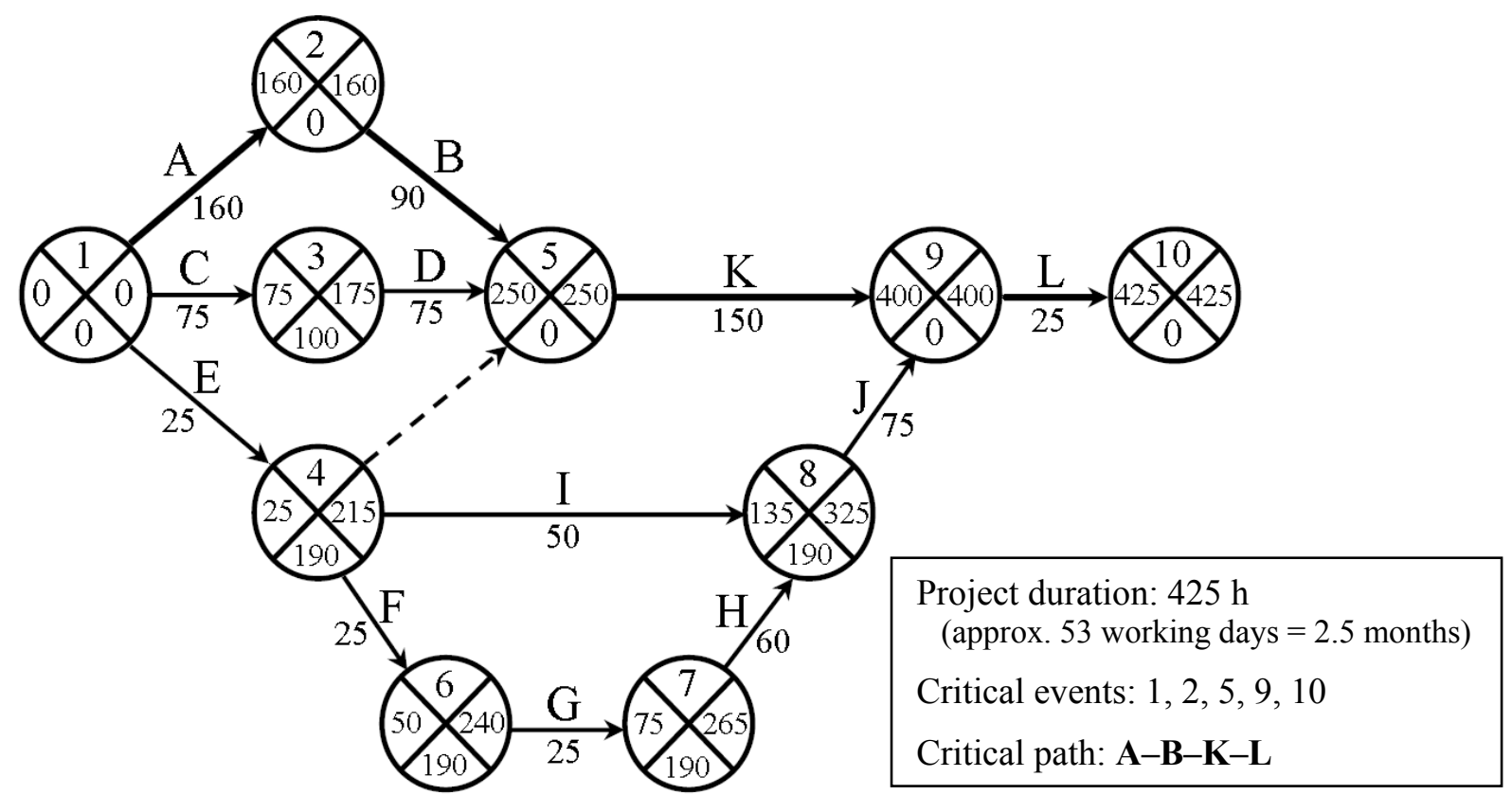

Figure 3: Complete project network diagram for given project data.

As a result we got 4 critical activities and 8 non-critical activities (which represent $49 \%$ of total project activities time - approx. one half). Activity periods (starting and finishing times) for critical activities are given in Table II.

Table II: Critical activities intervals (scheduled starting and finishing times).

\begin{tabular}{|c|c|c|}
\hline Activity & Start (h) & Finish (h) \\
\hline A & 0 & 160 \\
\hline B & 160 & 250 \\
\hline K & 250 & 400 \\
\hline L & 400 & 425 \\
\hline
\end{tabular}

All non-critical activities have some slack (min. 100 h, max. $250 \mathrm{~h} ; 175 \mathrm{~h}$ on average, which means approx. $41 \%$ of project duration); each activity may be delayed from its early start without delaying the finish of the project. To study the impact of possible delay of noncritical activities on the $C T I$ we have simulated three scenarios:

- non-critical activities are performed as soon as possible (case 1),

- non-critical activities start in the middle of the early start and the late start time interval (case 2),

- non-critical activities are performed as late as possible (case 3).

Activity periods (starting and finishing times) for non-critical activities and for all three cases are collected in Table III. 
Table III: Non-critical activities' intervals (scheduled starting and finishing times).

\begin{tabular}{|c|c|c|c|c|c|c|}
\hline \multirow{2}{*}{ Activity } & \multicolumn{2}{|c|}{ Case 1 } & \multicolumn{2}{c|}{ Case 2 } & \multicolumn{2}{c|}{ Case 3 } \\
\cline { 2 - 7 } & Start (h) & Finish (h) & Start (h) & Finish (h) & Start (h) & Finish (h) \\
\hline C & 0 & 75 & 50 & 125 & 100 & 175 \\
\hline D & 75 & 150 & 125 & 200 & 175 & 250 \\
\hline E & 0 & 25 & 95 & 120 & 190 & 215 \\
\hline F & 25 & 50 & 120 & 145 & 215 & 240 \\
\hline G & 50 & 75 & 145 & 170 & 240 & 265 \\
\hline H & 75 & 135 & 170 & 230 & 265 & 325 \\
\hline I & 25 & 75 & 150 & 200 & 275 & 325 \\
\hline J & 135 & 210 & 230 & 305 & 325 & 400 \\
\hline
\end{tabular}

For the calculations and simulation of cost-time profiles and cost-time investment we used Cost Time Profiler software, developed in 2006 at Virginia Tech (in the Center for High Performance Manufacturing, team: Rivera, Chen, Sturges, Valdes, Bedoya) for use on the Microsoft.NET Framework 2.0 platform.

Other important project data and necessary simplifications, limitations, constraints or presumptions are:

- number of working days per year is 252 ,

- the project starts with absolute certainty,

- as the project proceeds, no changes in plans occur,

- annual cost of capital rate is $10 \%$,

- raw materials and necessary tools for manufacturing are purchased using the JIT principle (at the begin of activity B and during the course of activity D),

- materials cost for trial run for production is $1000 \mathrm{EUR}$, tools cost is $5000 \mathrm{EUR}$, totally 6000 EUR,

- materials cost for regular production is 10000 EUR, additional tools cost is 2000 EUR, totally 12000 EUR (total costs of materials and tools represent approx. $23 \%$ of total project costs),

- hourly rates (in EUR) for the whole group of employees (between 1 and 13 persons in a group) engaged for the activities:
A: 45
B: 175
C: 28
D: 16
E: 38
F: 50
G: 50
H: 35
I: 32
J: 60
K: 150
L: 25

- potential use of new technology cannot cause any project delays due to lack of knowledge, training needs, and so on,

- other cost components, possible to be used in the software (maintenance cost, resources' price, resources' life, overhead rate, profit rate etc.) are neglected and taken as 0 (the influence of the parameters above is not measured and studied; basic machining equipment exists in the company and it is used for production of the entire products' range),

- all costs are entered in $10^{2}$ EUR (for better visibility in graphic presentations),

- all activities are finished exactly in planned time, achieved products' quality is always acceptable,

- all required resources (people, funds, equipment, information, facilities etc.) are available in any given time period, regardless of uncertain economic times, general economic disturbances or business conditions.

Two data entry screens of Cost Time Profiler software are shown in Fig. 4. 


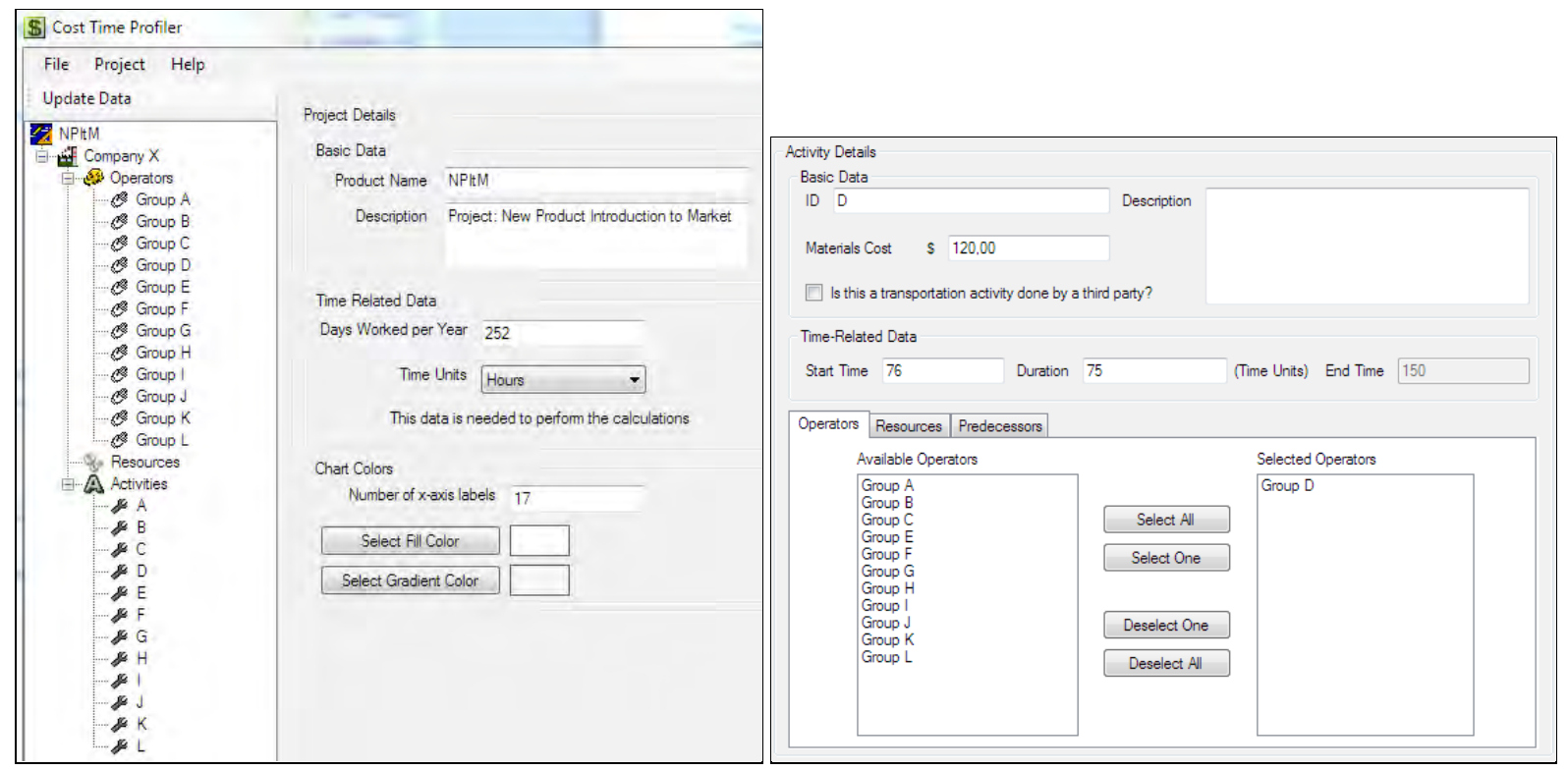

Figure 4: Cost Time Profiler data entry screens (selected).

Critical activities are without any slack, so their share in the observed $C T I$ is fixed. First we simulate the $C T I$ only for critical path activities $(\mathrm{A}, \mathrm{B}, \mathrm{K}, \mathrm{L})$ without costs for materials and tools, while the purchase of them is flexible. See the results in Fig. 5.

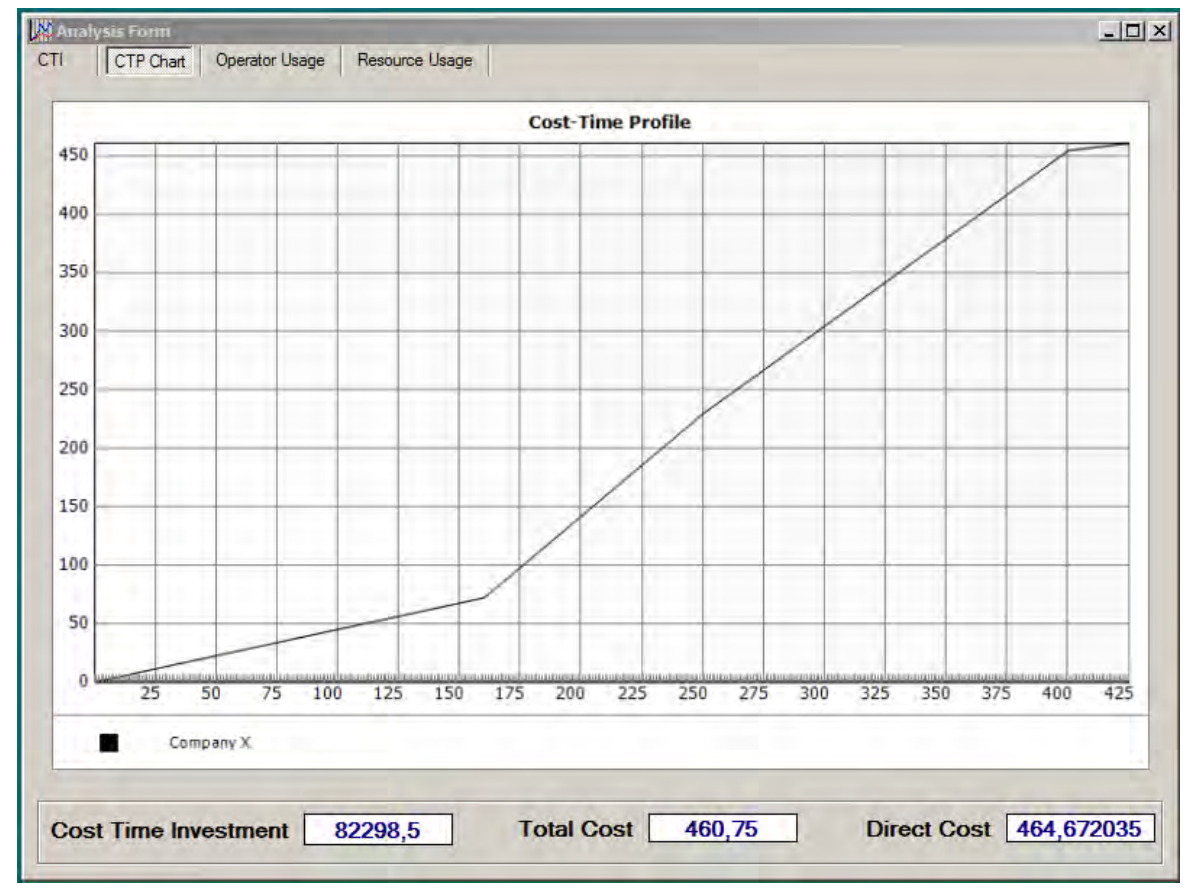

$C T I_{f i x}=8229850 \mathrm{EUR} \cdot \mathrm{h}$

Figure 5: Fixed part of the cost-time investment (critical path $C T I$ ).

\subsection{Case 1}

Non-critical activities start at earliest possible start times. The CTI is calculated for all activities and for all considered costs (Fig. 6). Project total cost: 79025 EUR. This is the same in all studied cases. Fixed part of the CTI denotes $43 \%$ of the total CTI. 


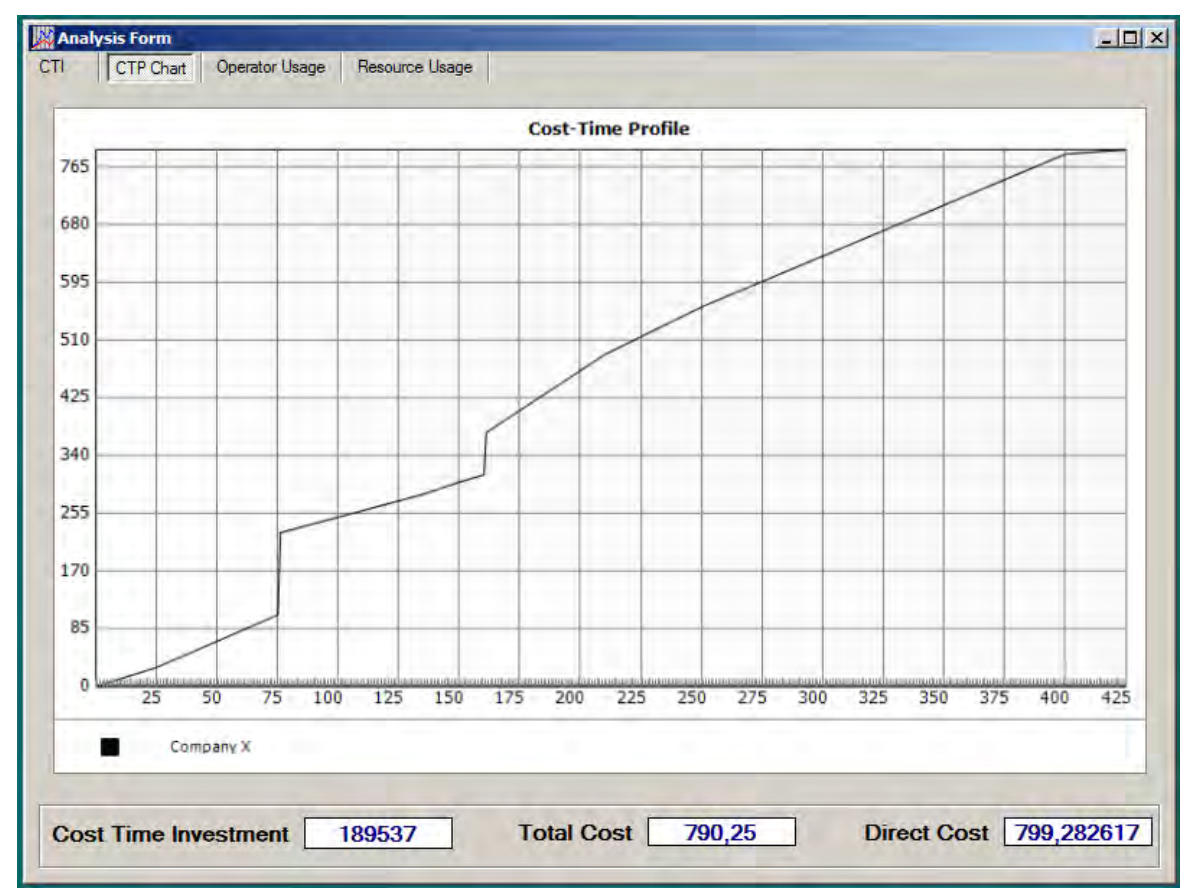

$C T I_{1}=18953700 \mathrm{EUR} \cdot \mathrm{h}$

Figure 6: Project cost-time profile / investment for case 1.

\subsection{Case 2}

Non-critical activities start at time which is delayed for $50 \%$ of slack (after the earliest possible start time). See Fig. 7. Fixed part of the CTI denotes $52 \%$ of the total CTI.

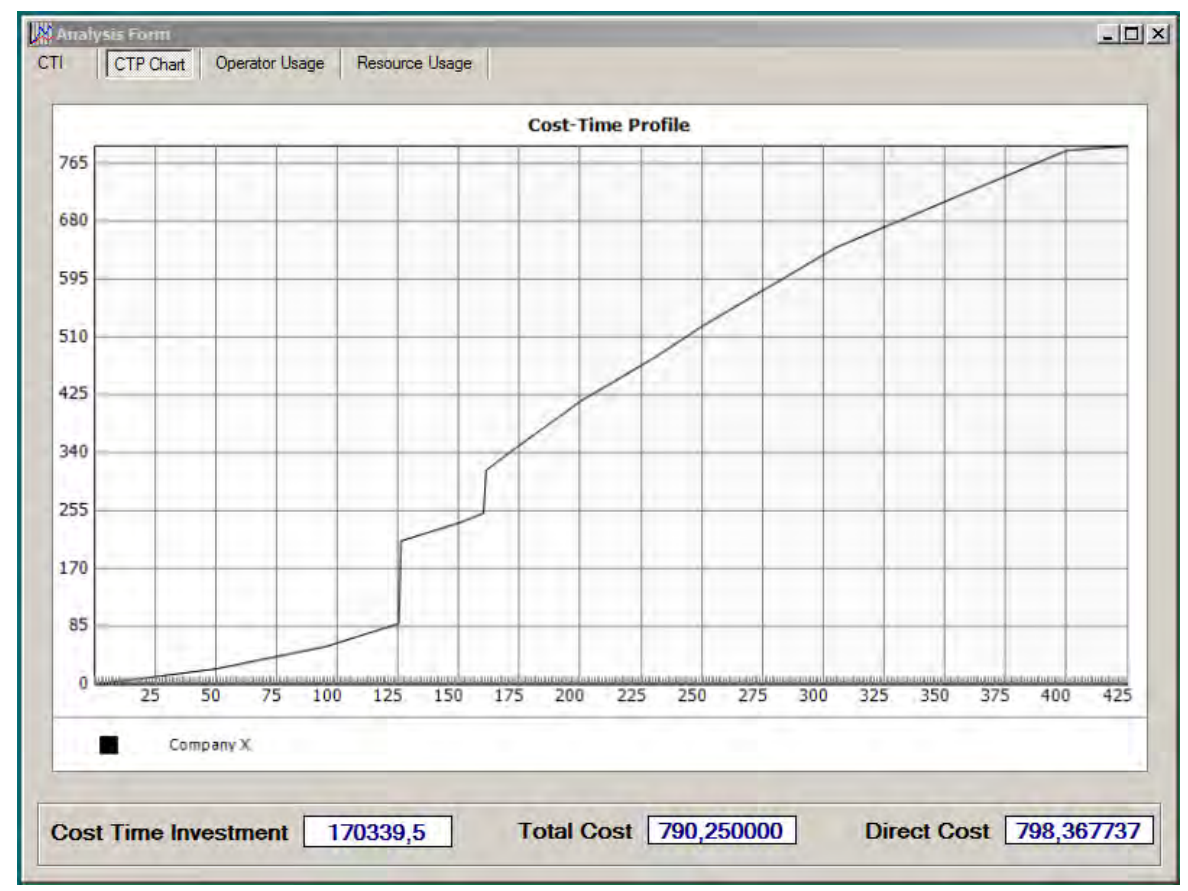

$C T I_{2}=17033950 \mathrm{EUR} \cdot \mathrm{h}$

Figure 7: Project cost-time profile / investment for case 2.

\subsection{Case 3}

Non-critical activities start at latest possible start times giving the smallest $C T I$ (Fig. 7). Fixed part of the $C T I$ denotes $54 \%$ of the total $C T I$. 


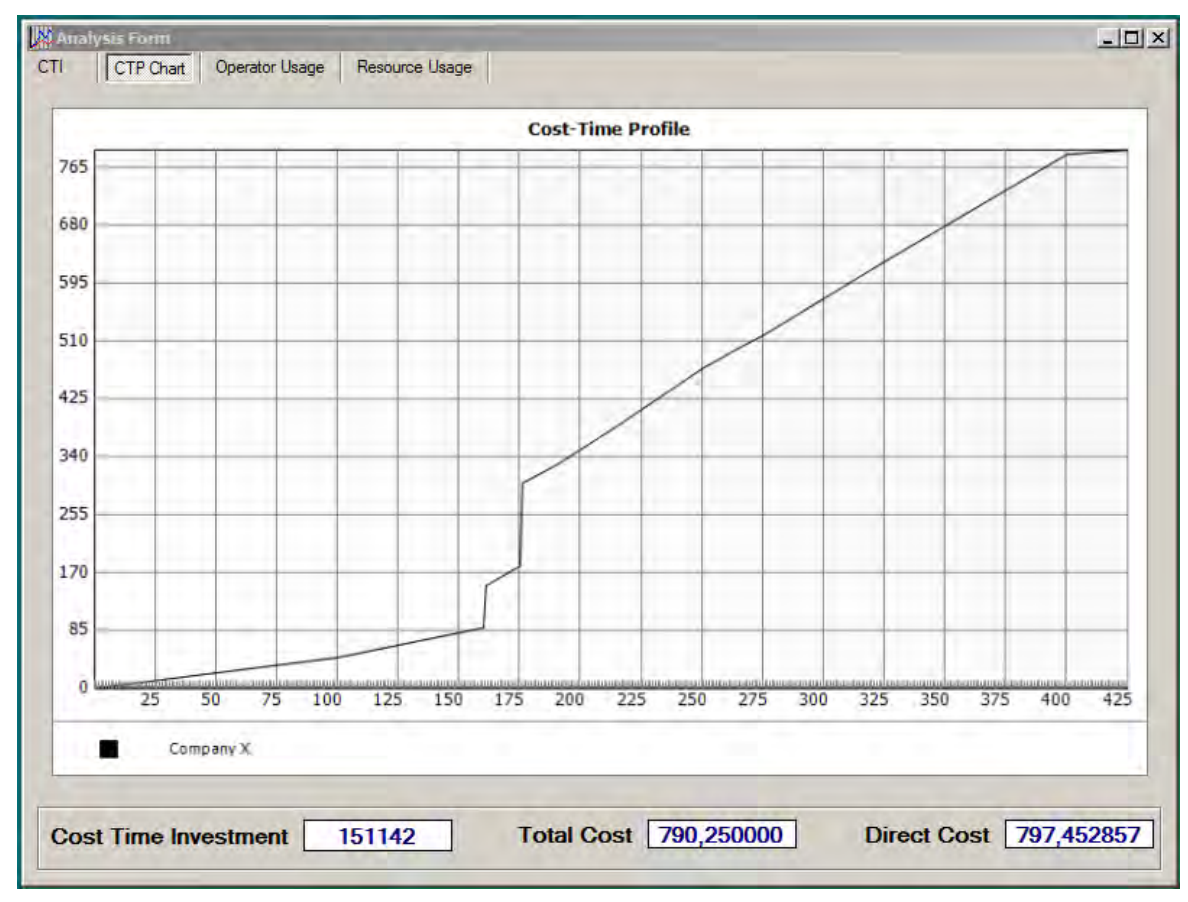

$\mathrm{CTI}_{3}=15114200 \mathrm{EUR} \cdot \mathrm{h}$

Figure 7: Project cost-time profile / investment for case 3.

\section{DISCUSSION}

For the comparison of all three basic cases the $C T I$ value is divided into two parts: $C T I_{f i x}$ and $C T I_{\text {var }}$. The influence of performing times of non-critical activities (always our planning decision) on the $C T I$ value is measured using the variable parts of $C T I$.

$$
C T I=C T I_{f i x}+C T I_{\text {var }}
$$

The results for all three cases are collected in Table IV. With the quotients of $C T I_{v a r}$ of different cases the effect could be measured.

Table IV: CTI simulation results.

\begin{tabular}{|l|c|c|c|}
\cline { 2 - 4 } \multicolumn{1}{c|}{} & Case 1 & Case 2 & Case 3 \\
\hline $\boldsymbol{C T I}($ EUR $h)$ & 18953700 & 17033950 & 15114200 \\
\hline $\boldsymbol{C T I}_{\text {var }}($ EUR $h)$ & 10723850 & 8804100 & 6884350 \\
\hline$\frac{C T I_{1}}{C T I_{3}}=125.4 \%$ & $\frac{C T I_{\text {var } 1}}{C T I_{\text {var } 3}}=155.8 \%$
\end{tabular}

The difference between the best and the worst result should not be overlooked. To remember: in our case study project non-critical activities duration represent one half of the sum of all project activities duration and have an average slack of $41 \%$ of project duration. So, during the project execution we must tend to the implementation of JIT principles regarding the scheduling of all non-critical activities. Such actions also contribute to the lean project philosophy.

Optimal total $C T I$ value $\left(\mathrm{CTI}_{3}\right)$ in amount of 15114200 EUR'h in a period of 425 hours means that we invest (locked-up capital) in that time on average 35563 EUR daily (total project cost is 79025 EUR). In the most unfavourable case (case 1) we have on average 44597 EUR invested during the whole project duration.

Differences between the direct costs are negligible (max. $0.2 \%$ ). 
Additionally we have simulated the case (as a continuation of case 3 ) when all the materials and tools are purchased at the beginning of the project (total materials and tools cost: 18000 EUR, approx. $23 \%$ of total project cost). Total CTI is 18174200 EUR'h for that case (Fig. 8), which means $20.2 \%$ more of locked-up capital.

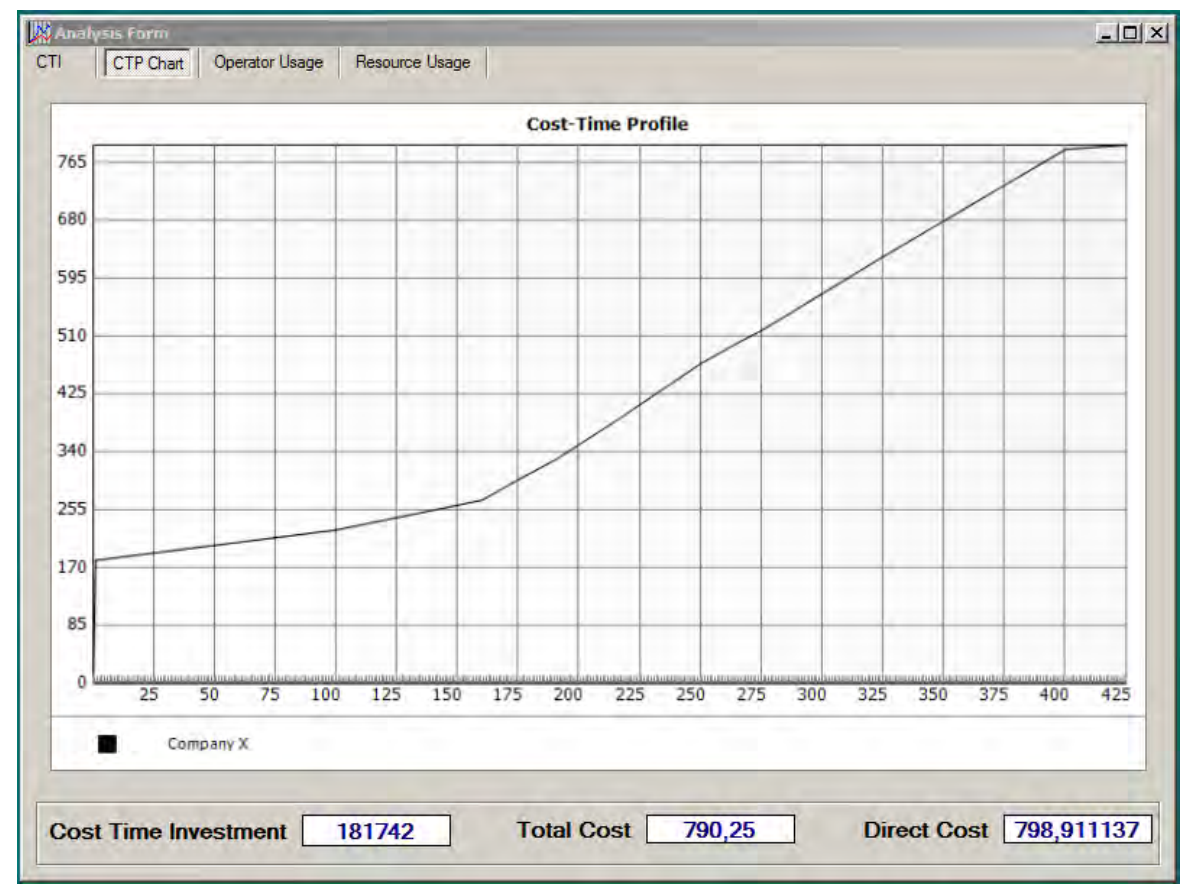

Figure 8: Project cost-time profile / investment (all the materials and tools are purchased at the beginning of the project).

\section{CONCLUSION}

The business world today is very complex. Projects are one of the basic means by which a company achieves its competitive advantage and successful business operations. Project oriented companies very rarely use cost-time profile tools. Money savings and reduced costtime investments are extremely important in the crisis time and contribute to the effectiveness of the company.

In the paper we have dealt with a simple project of a new product introduction to the market. We have tested the impact of non-critical activities execution time periods to project's cost-time investment. Using slack for delay of such activities brings essential improvements. Also the JIT purchase of tools and materials is necessary. But we must be aware of all potential, associated risks and uncertainty.

Our future work in the field of cost-time profiles will include the investigation of more complex projects, involving subcontractors, detailed observation of cost components, resource constraints, project schedule crashing etc.

\section{REFERENCES}

[1] Pinto, J. (2007). Project management: achieving competitive advantage, Pearson Education, Upper Saddle River

[2] Bender, M. B. (2010). A manager's guide to project management: Learn how to apply best practices, Pearson Education, Inc., New Jersey 
[3] Kerzner, H. (2009). Project management: A systems approach to planning, scheduling, and controlling, John Wiley \& Sons, New York

[4] Wysocki, R. K. (2009). Effective project management: Traditional, agile, extreme, Wiley Publishing, Indianapolis

[5] Nicholas, J. M.; Steyn, H. (2012). Project management for engineering, business and technology, Routledge, Oxon

[6] Lock, D. (2008). Project management, Gower Publishing, Aldershot

[7] Atkinson, R. (1999). Project management: cost, time, and quality, two best guesses and a phenomenon, its time to accept other success criteria, International Journal of Project Management, Vol. 17, No. 6, 337-342, doi:10.1016/S0263-7863(98)00069-6

[8] Baccarini, D. (1999). The logical framework method for defining project success, Project Management Journal, Vol. 30, No. 4, 25-32

[9] Ika, L. A. (2009). Project success as a topic in project management journals, Project Management Journal, Vol. 40, No. 4, 6-19, doi:10.1002/pmj.20137

[10] Pinto, J. K.; Slevin, D. P. (1988). Project success: definitions and measurement techniques, Project Management Journal, Vol. 19, No. 1, 67-75

[11] Jugdev, K.; Muller, R. (2005). A retrospective look at our evolving understanding of project success, Project Management Journal, Vol. 36, No. 4, 19-31

[12] Wateridge, J. (1998). How can IS/IT projects be measured for success?, International Journal of Project Management, Vol. 16, No. 1, 59-63, doi:10.1016/S0263-7863(97)00022-7

[13] Zhao, R. (2012). Simulation-based environmental cost analysis for work-in-process, International Journal of Simulation Modelling, Vol. 11, No. 4, 211-224, doi:10.2507/IJSIMM11(4)4.218

[14] Bannerman, P. L. (2008). Defining project success: A multilevel framework, Proceedings of the PMI research conference, 1-14

[15] McLeod, L.; Doolin, B.; MacDonell, S. G. (2012). A perspective-based understanding of project success, Project Management Journal, Vol. 43, No. 5, 68-86, doi:10.1002/pmj.21290

[16] Kusar, J.; Bradesko, L.; Duhovnik, J.; Starbek, M. (2008). Project management of product development, Strojniki vestnik - Journal of Mechanical Engineering, Vol. 54, No. 9, 588-606

[17] Manotas Duque, D. F.;Rivera Cadavid, L. (2010). Activity scheduling for cost-time investment optimization in project management, Proceedings of the $4^{\text {th }}$ International Conference on Industrial Engineering and Industrial Management, 1453-1461

[18] Fooks, J. H. (1993). Profiles for performance: total quality methods for reducing cycle time, Addison-Wesley, Reading

[19] Rivera, L. (2006). Inter-Enterprise Cost-Time Profiling, PhD Dissertation, Virginia Polytechnic Institute and State University, Blacksburg

[20] Chaudhari, G. (2007). Cost-time profiling as a tool in value engineering, Value World, Vol. 30, No. $1,1-8$

[21] Gracanin, D.; Lalic, B.; Beker, I.; Lalic, D.; Buchmeister, B. (2013). Cost-time profile simulation for job shop scheduling decisions, International Journal of Simulation Modelling, Vol. 12, No. 4, 213-224, doi:10.2507/IJSIMM12(4)1.237

[22] Gracanin, D.; Buchmeister, B.; Lalic, B. (2014). Using cost-time profile for value stream optimization, Procedia Engineering, Vol. 69, 1225-1231, doi:10.1016/j.proeng.2014.03.113 